\title{
TORSIONAL BUCKLING OF THIN-WALLED BEAMS IN PRESENCE OF BIMOMENT INDUCED BY AXIAL LOADS
}

\author{
Aleksandar Prokić, Rastislav Mandić, Martina Vojnić-Purčar, Radomir Folić
}

Original scientific paper

In this paper the influence of the bimoment induced by external axial loads on the elastic torsional buckling of thin-walled beams with open cross-section is studied. The governing differential equations of a deformed thin-walled beam consistent with Vlasov's classical assumptions are derived applying the principle of virtual displacements. It is shown that in the cross sections with lack of symmetry the bimoment can considerably affect the torsional buckling load. The obtained results are verified using ANSYS finite element software.

Keywords: bimoment; thin-walled beams; torsional buckling

Utjecaj bimomenta na uvojno izvijanje tankostjenih štapova pod aksijalnim opterećenjem

Izvorni znanstveni članak

U članku je proučen utjecaj bimomenta na stabilnost tankostjenog štapa s otvorenim poprečnim presjekom uslijed vanjskog aksijalnog opterećenja. Primjenom principa virtualnih pomjeranja izvedene su diferencijalne jednadžbe deformiranog tankostjenog elementa u skladu s klasičnim pretpostavkama Vlasova. Pokazano je da kod poprečnih presjeka koji nemaju os simetrije bimomenat može značajno utjecati na uvojnu kritičnu silu. Dobiveni rezultati su provjereni primjenom programa ANSYS.

Ključne riječi: bimoment; tankostjeni štapovi; uvojno izvijanje

\section{Introduction}

Thin-walled beams of open cross-section are widely used in structural engineering due to high bearing strength when compared to self weight. The assessment of elastic stability of thin-walled beams is one of the most important issues in the analysis of thin-walled structures. For hot rolled sections which in the most cases, according to Eurocode 3 [1] belong to classes 1 or 2, the webthickness and flange-thickness rations satisfy the requirements for preventing local buckling and distortion of the cross-section. The global stability of centrically or eccentrically compressed members is in the most cases the result of flexural buckling around minor axis. The analysis of pure torsional buckling may be of interest in sections with low torsional rigidity and/or in the cases when external supports decrease flexural but not torsional buckling lengths. The analysis of these elements is mainly covered by the assumptions of the classical Vlasov's theory [2]. In plated girders the longitudinal stiffeners are added to prevent local buckling while distortion is restrained by cross-frames and diaphragms. The cold form steel elements have very small slenderness and they belong to the cross-section class 4 , so the consideration of distortional and local buckling effect is of great importance. The finite element method [3] or the finite strip method [4] as well as the models based on one dimensional generalized beam theory (GBT) [5] can be applied for the analysis of these elements.

In this paper, starting from the assumptions of the classical Vlasov's theory, the stability of axially compressed members is studied in the specific case of asymmetric cross-sections when the loading point of the external axial force has a non zero value of warping function. According to our knowledge there is a lack of detailed investigation in this area. Focussing on the pure torsional buckling of a beam with $Z$ cross-section, it is demonstrated that the bimoment produced by axial forces has the effect which is not negligible, so the critical force is increased or decreased with respect to the traditional approach of stability analysis with the force resultant and without bimoment.

\section{Kinematics of deformation}

The assumptions of classical (Vlasov's) theory for thin-walled beams with open cross-sections are used: cross-section is assumed to be perfectly rigid in its own plane; shear deformation in the middle surface of each thin-walled plate is neglected; there is no shear deformation of thin-walled plates in the plane $(z-n)$ perpendicular to the middle surface.

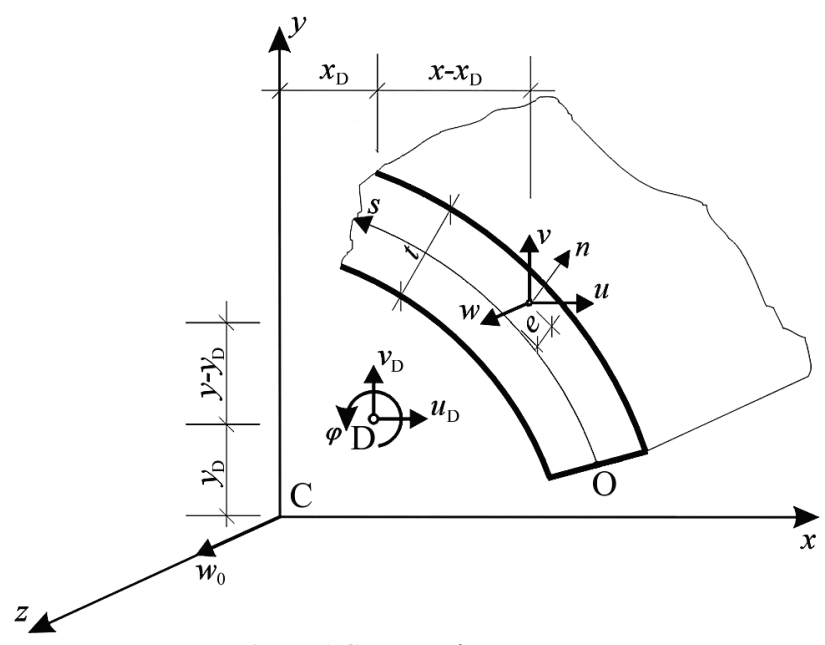

Figure 1 Cross-section geometry

According to the adopted assumptions in a straight thin-walled beam with longitudinal axis $z$, the displacement components $(u, v, w)$ of an arbitrary point of a thin-walled beam (Fig. 1), in the directions $x, y$ and $z$, are given with 


$$
\begin{aligned}
& u=u_{\mathrm{D}}-\left(y-y_{\mathrm{D}}\right) \varphi, \\
& v=v_{\mathrm{D}}+\left(x-x_{\mathrm{D}}\right) \varphi, \\
& w=w_{0}-u_{\mathrm{D}}^{\prime} x-v_{\mathrm{D}}^{\prime} y-\varphi^{\prime} \omega .
\end{aligned}
$$

Note that $x, y$ coincide with the principal axes in the plane of the cross-section before deformation. In Eq. (1) $u_{\mathrm{D}}(z)$, $v_{\mathrm{D}}(z)$ are displacements of the shear centre $\mathrm{D}, w_{0}(z)$ is the translation of the cross-section along $z, \varphi(z)$ is the infinitesimal angle of twist around shear centre, while $\omega(x, y)$ is the normalized warping function. Primes denote the total derivative with respect to $z$.

The components of finite strain tensor referring to the axis $z$ are given with

$$
e_{z \alpha}=\frac{1}{2}\left(\boldsymbol{r}_{, z}^{\mathrm{T}} \boldsymbol{r}_{, \alpha}-\delta_{z \alpha}\right) \quad \alpha=e, s, z
$$

where $\boldsymbol{r}$ is the position vector of an arbitrary point after deformation

$$
\boldsymbol{r}=\{x+u, \quad y+v, \quad z+w\}^{\mathrm{T}},
$$

$\delta_{z \alpha}$ is Kronecker delta symbol, while $s$ and $e$ are the coordinates along the middle line of the cross-section and perpendicular to the middle surface. The virtual strains are obtained from the variations of strain components

$$
\delta e_{z \alpha}=\frac{1}{2}\left(\delta \boldsymbol{r}_{, z}^{\mathrm{T}} \boldsymbol{r}_{, \alpha}+\boldsymbol{r}_{, z}^{\mathrm{T}} \delta \boldsymbol{r}_{, \alpha}\right)
$$

The virtual displacement along axes $x$ and $y$ are

$$
\begin{aligned}
& \delta u=\delta u_{\mathrm{D}}-\left(y+v-y_{\mathrm{D}}\right) \delta \varphi, \\
& \delta v=\delta v_{\mathrm{D}}+\left(x+u-x_{\mathrm{D}}\right) \delta \varphi .
\end{aligned}
$$

Note that $\delta \varphi$ denotes the virtual rotation around the initial longitudinal axes. Virtual displacements along the beam $z$ axis are derived taking into account the assumption that there is no shear deformation in the middle surface $s-z$ and in the plane $z$-e, i.e. for $e=0, \delta e_{z s}=0$ and $\delta e_{z n}=0$, which yields

$$
\begin{aligned}
& \delta w=\delta w_{0}-\delta u_{\mathrm{D}}^{\prime}(x+u)-\delta v_{\mathrm{D}}^{\prime}(y+v)- \\
& -\delta \varphi^{\prime}\left[\omega+u_{\mathrm{D}}\left(y-y_{\mathrm{D}}\right)-v_{\mathrm{D}}\left(x-x_{\mathrm{D}}\right)\right] .
\end{aligned}
$$

Finally, from Eq. (4) the virtual shear strain $\delta e_{z s}$ and the virtual strain $\delta e_{z z}$ along the beam axis are

$$
\begin{aligned}
& \delta e_{z s}=\delta \varphi^{\prime} e \\
& \delta e_{z z}=\delta w,_{z}+\delta u,{ }_{z} u,_{z}+\delta v,_{z} v,_{z}
\end{aligned}
$$

where in the second equation the higher order term $w_{, z} \delta w_{, z}$ is neglected. The remaining virtual strains components are zero.

\section{Equations of equilibrium}

The equilibrium conditions of the deformed element could be derived using the principle of virtual work, applying variation of displacements of infinitesimal element between the cross-sections $z$ and $z+\mathrm{d} z$. The virtual work $\delta W_{\mathrm{E}}$ of external forces per unit length is

$$
\delta W_{\mathrm{E}}=\int_{A}\left(\boldsymbol{\sigma}_{, z}^{\mathrm{T}} \delta \boldsymbol{u}+\boldsymbol{\sigma}^{\mathrm{T}} \delta \boldsymbol{u}_{, z}\right) \mathrm{d} A+\int_{S} \overline{\boldsymbol{p}}^{\mathrm{T}} \delta \boldsymbol{u} \mathrm{d} s,
$$

where $\boldsymbol{u}^{\mathrm{T}}=\{u, v, w\}$ denotes the displacement vector, $\sigma^{\mathrm{T}}=\left\{t_{x z}, t_{y z}, t_{z z}\right\}$ is the stress vector with the components resolved along the initial unit basis and $\overline{\boldsymbol{p}}^{\mathrm{T}}=\left\{\bar{p}_{x}, \bar{p}_{y}, \bar{p}_{z}\right\}$ are the surface forces applied along the middle surface. The components $t_{z x}, t_{z y}$ and $t_{z z}$ are obtained from the true stress components $\sigma_{z x}, \sigma_{z y}$ and $\sigma_{z z}$ by the transformation due to infinitesimal rotations around axes $x, y$ and $z$

$$
\left\{\begin{array}{l}
t_{z x} \\
t_{z y} \\
t_{z z}
\end{array}\right\}=\left[\begin{array}{ccc}
1 & -\varphi & u,_{z} \\
\varphi & 1 & v,_{z} \\
-u,_{z} & -v,_{z} & 1
\end{array}\right]\left\{\begin{array}{c}
\sigma_{z x} \\
\sigma_{z y} \\
\sigma_{z z}
\end{array}\right\}
$$

The work of internal forces per unit length is

$\delta W_{\mathrm{I}}=-\int_{A}\left(\sigma_{z z} \delta e_{z z}+2 \sigma_{z S} \delta e_{z s}\right) \mathrm{d} A$.

In Eq. (10) the normal and shear stress are found from deformation, Eq. (2), retaining only linear terms

$$
\begin{aligned}
& \sigma_{z z}=E\left(w_{0}^{\prime}-u_{\mathrm{D}}^{\prime \prime} x-v_{\mathrm{D}}^{\prime \prime} y-\varphi^{\prime \prime} \omega\right), \\
& \sigma_{z s}=2 G \varphi^{\prime} e_{z s},
\end{aligned}
$$

where $E=$ Young's modulus and $G=$ shear modulus.

Using the total virtual work $\delta W_{\mathrm{E}}+\delta W_{\mathrm{I}}=0$ and by neglecting the second powers of the displacement gradients, the following equations of equilibrium according to the second order theory are obtained

$$
\begin{aligned}
& N^{\prime}-\underline{\left(Q_{x} u_{\mathrm{D}}^{\prime}+Q_{y} v_{\mathrm{D}}^{\prime}+T_{\mathrm{D}} \varphi\right)^{\prime}}+p_{z}=0 \\
& Q_{x}^{\prime}+\left[N\left(u_{\mathrm{D}}^{\prime}+y_{\mathrm{D}} \varphi^{\prime}\right)-M_{y} \varphi^{\prime}-Q_{y} \varphi\right]^{\prime}+p_{x}=0 \\
& Q_{y}^{\prime}+\left[N\left(v_{\mathrm{D}}^{\prime}-x_{\mathrm{D}} \varphi^{\prime}\right)+M_{x} \varphi^{\prime}+Q_{x} \varphi\right]^{\prime}+p_{y}=0 \\
& M_{x}^{\prime}-Q_{x}+m_{x}-\varphi\left(M_{y}^{\prime}-Q_{y}+m_{y}\right)+ \\
& +\underline{\left(N^{\prime}+p_{z}\right)}\left(u_{\mathrm{D}}+y_{\mathrm{D}} \varphi\right)=0 \\
& M_{y}^{\prime}-Q_{y}+m_{y}+\varphi \underline{\left(M_{x}^{\prime}-Q_{x}+m_{x}\right)}+ \\
& +\underline{\left(N^{\prime}+p_{z}\right)}\left(v_{\mathrm{D}}-x_{\mathrm{D}} \varphi\right)=0 \\
& M_{\omega}{ }^{\prime}-T_{\omega}+m_{\omega}+u_{\mathrm{D}} \underline{\left(M_{y}^{\prime}-Q_{y}-m_{y}\right)}- \\
& -v_{\mathrm{D}}\left(M_{x}^{\prime}-Q_{x}-m_{x}\right)- \\
& -\left(N^{\prime}+p_{z}\right)\left(u_{\mathrm{D}} y_{\mathrm{D}}-v_{\mathrm{D}} x_{\mathrm{D}}\right)=0
\end{aligned}
$$




$$
\begin{aligned}
T_{\mathrm{D}}^{\prime} & +\left[Q_{y} u_{\mathrm{D}}-Q_{x} v_{\mathrm{D}}-u_{\mathrm{D}}^{\prime}\left(M_{y}-N y_{\mathrm{D}}\right)\right]^{\prime}+ \\
& +\left[v_{\mathrm{D}}^{\prime}\left(M_{x}-N x_{\mathrm{D}}\right)\right]^{\prime}+ \\
& +\left[\varphi^{\prime}\left(N i_{\mathrm{D}}^{2}+2 M_{x} \beta_{x}+2 M_{y} \beta_{y}+M_{\omega} \beta_{\omega}\right)\right]^{\prime}+ \\
& +m_{\mathrm{D}}+p_{y} u_{\mathrm{D}}-p_{x} v_{\mathrm{D}}-\varphi \tilde{m}_{\mathrm{D}}=0
\end{aligned}
$$

In Eqs. (12) $N, M_{x}, M_{y}, M_{\omega}$ denote the axial force, bending moments and bimoment; $Q_{x}, Q_{y}, T_{D}$ are shear forces and torsional moment around shear centre; $p_{x}, p_{y}, p_{z}$ are distributed forces; $m_{x}, m_{y}, m_{\mathrm{D}}$ denote distributed moments while $m_{\omega}$ is the external distributed bimoment. Neglecting the contribution of shear stresses to the equilibrium in $z$ direction, the underlined term in Eq. (12.1) can be omitted. In addition, it is assumed that in products of static and deformation variables the static values are found from the first order theory. The result of this assumption is that the underlined terms in Eqs. (12.46 ) are equal to zero. Finally, considering Eqs. (11) and the definition of sectional forces (see Appendix), the following differential equations are obtained

$$
\begin{aligned}
& E A w_{0}^{\prime \prime}=-p_{z} \\
& E I_{x x} u_{\mathrm{D}}^{I V}-\left[N\left(u_{\mathrm{D}}^{\prime}+y_{\mathrm{D}} \varphi^{\prime}\right)\right]^{\prime}+\left(M_{y} \varphi\right)^{\prime \prime}+\left(m_{y} \varphi\right)^{\prime}= \\
& =p_{x}+m_{x}^{\prime} \\
& E I_{y y} v_{\mathrm{D}}^{I V}-\left[N\left(v_{\mathrm{D}}^{\prime}-x_{\mathrm{D}} \varphi^{\prime}\right)\right]^{\prime}-\left(M_{x} \varphi\right)^{\prime \prime}-\left(m_{x} \varphi\right)^{\prime}= \\
& =p_{y}+m_{y}^{\prime} \\
& E I_{\omega \omega} \varphi^{I V}-G K \varphi^{\prime \prime}-\left[\varphi ^ { \prime } \left(N i_{\mathrm{D}}^{2}+2 M_{x} \beta_{x}+2 M_{y} \beta_{y}+\right.\right. \\
& +\frac{\left.\left.M_{\omega} \beta_{\omega}\right)\right]^{\prime}-y_{\mathrm{D}}\left(N u_{\mathrm{D}}^{\prime}\right)^{\prime}+x_{\mathrm{D}}\left(N v_{\mathrm{D}}^{\prime}\right)^{\prime}+u_{\mathrm{D}}^{\prime \prime} M_{y}-}{} \quad-v_{\mathrm{D}}^{\prime \prime} M_{x}+u_{\mathrm{D}}^{\prime} m_{y}-v_{\mathrm{D}}^{\prime} m_{x}+\varphi \tilde{m}_{\mathrm{D}}=m_{\mathrm{D}}+m_{\omega}^{\prime}
\end{aligned}
$$

The Eqs. (13.2) to (13.4) define the coupled bending and torsion according to the linearized second order theory. The underlined term in Eq. (13.4) represents the influence of bimoment due to second order effect which is important only in the cross sections with lack of symmetry, i.e. $\beta_{\omega} \neq 0$. In many classical books referring to stability of thin-walled beams (e.g. $[6 \div 9]$ ) the influence of $M_{\omega}$ is ignored. It is recognized by Vlasov [2] and by some authors (e.g. [10 $\div 12]$ ) and in [13] where the influence of the bimoment on lateral buckling, caused by the transverse force, is considered. In this paper, as we underlined in the introduction, the influence of the bimoment on torisonal stability of axially loaded thinwalled beams is studied.

\section{Stability analysis - axial loading}

The stability of thin walled-beam is defined with the homogenous part of Eqs. (13). In the case of a concentrated compressive axial force $P$ with eccentricities $e_{x}, e_{y}$ the thin-walled beam is stressed with $N=-P$, constant bending moments $M_{x}=-P e_{x}, M_{y}=-P e_{y}$ and the variable bimoment $M_{\omega}(z)=\lambda(z) M_{\omega 0}$ where $M_{\omega 0}=-P \omega_{(P)}$ is the bimoment at the end cross-sections, $\omega_{(P)}$ is the warping function of the loading point, while $\lambda(\mathrm{z})$ is the pre-buckling bimoment distribution function. The Eqs. $(13.2-4)$ reduce to

$$
\begin{aligned}
E I_{x x} u_{\mathrm{D}}^{I V} & +P u_{\mathrm{D}}^{\prime \prime}+P\left(y_{\mathrm{D}}-e_{y}\right) \varphi^{\prime \prime}=0 \\
E I_{y y} v_{\mathrm{D}}^{I V} & +P v_{\mathrm{D}}^{\prime \prime}-P\left(x_{\mathrm{D}}-e_{x}\right) \varphi^{\prime \prime}=0 \\
E I_{\omega \omega} \varphi^{I V}-\left[G K-P\left(i_{\mathrm{D}}^{2}+2 e_{x} \beta_{x}+2 e_{y} \beta_{y}\right)\right] \varphi^{\prime \prime}+ & \\
& +P \omega_{(P)} \beta_{\omega}\left(\lambda \varphi^{\prime}\right)^{\prime}+ \\
& +P\left(y_{\mathrm{D}}-e_{y}\right) u_{\mathrm{D}}^{\prime \prime}-P\left(x_{\mathrm{D}}-e_{x}\right) v_{\mathrm{D}}^{\prime \prime}=0
\end{aligned}
$$

Note that in Eqs. (14) $u_{D}, v_{\mathrm{D}}$ and $\varphi$ denote displacements due to buckling while the pre-buckling deformations are neglected.

The pre-buckling bimoment distribution function $\lambda(z)$ is calculated from the well known differential equation of warping torsion in undeformed configuration (e.g. see [7]). At the beam ends $\lambda=1,0$ while $0<\lambda(z) \leq 1,0$ for $0 \leq z$ $\leq L$, where $L$ is the beam length.

In order to obtain closed form solution of the buckling load from Eqs. (14), the variable distribution of bimoment is approximated with its average value $M_{\omega}(z)=\lambda_{\mathrm{m}} M_{\omega 0}$, where $\lambda_{\mathrm{m}}$ is the mean value of $\lambda(z)$ in the range $0 \leq z \leq L$. For a simply supported beam the end conditions are

$\left.\begin{array}{l}u_{\mathrm{D}}=v_{\mathrm{D}}=\varphi=0 \\ u_{\mathrm{D}}^{\prime \prime}=v_{\mathrm{D}}^{\prime \prime}=\varphi^{\prime \prime}=0\end{array}\right\}$ for $z=0$ and $z=L$,

while the parameter $\lambda_{\mathrm{m}}$ is given with

$$
\lambda_{\mathrm{m}}=2 \frac{\cosh (k L)-1}{k L \sinh (k L)}, k=\sqrt{\frac{G K}{E I_{\omega \omega}}} .
$$

The boundary conditions (i.e. Eqs. (15)), are satisfied with the following buckling displacement field

$$
\left\{\begin{array}{l}
u_{\mathrm{D}} \\
v_{\mathrm{D}} \\
\varphi
\end{array}\right\}=\left\{\begin{array}{l}
U_{n} \\
V_{n} \\
\Phi_{n}
\end{array}\right\} \sin \frac{n \pi z}{L} .
$$

Following the well-known procedure [6] and substituting Eqs. (17) into Eqs. (14) yields (for each $n=1$, $2 \ldots)$ the buckling equation

$$
\left|\begin{array}{ccc}
P-E I_{x x} \frac{n^{2} \pi^{2}}{L^{2}} & 0 & P\left(y_{\mathrm{D}}-e_{y}\right) \\
0 & P-E I_{y y} \frac{n^{2} \pi^{2}}{L^{2}} & -P\left(x_{\mathrm{D}}-e_{x}\right) \\
P\left(y_{\mathrm{D}}-e_{y}\right) & -P\left(x_{\mathrm{D}}-e_{x}\right) & P d_{2}^{*}-d_{1}^{*}
\end{array}\right|=0,
$$




$$
\begin{aligned}
& d_{1}^{*}=E I_{\omega \omega} \frac{n^{2} \pi^{2}}{L^{2}}+G K, \\
& d_{2}^{*}=i_{\mathrm{D}}^{2}+2 e_{x} \beta_{x}+2 e_{y} \beta_{y}+\lambda_{\mathrm{m}} \beta_{\omega} \omega_{(P)} .
\end{aligned}
$$

In the general case of flexural-torsional buckling, the Eq. (18) is in the form polynomial of the third order.

If the axial load is applied at the shear centre the pure torsional critical load is $P_{\mathrm{cr}}=d_{1}^{*} / d_{2}^{*}$ which for the pointsymmetrical cross-sections $(\mathrm{C} \equiv \mathrm{D})$ has the following lowest $(n=1)$ value

$$
P_{\mathrm{cr}}=\frac{E I_{\omega \omega} \frac{\pi^{2}}{L^{2}}+G K}{i_{\mathrm{D}}^{2}+\lambda_{\mathrm{m}} \beta_{\omega} \omega_{(P)}} .
$$

The second term in the denominator of Eq. (20) represents the influence of the bimoment. Depending on the sign of the warping function in the loading point the buckling force is increased or decreased with respect to the critical force obtained by the classical approach [6] when the presence of the bimoment is ignored.

\section{$5 \quad$ Numerical examples}

A straight simply supported thin-walled beam with $Z$ cross-section (Fig. 2a) is analyzed in order to investigate the effect of the bimoment on the elastic torsional buckling. The following elastic constants are used: Young's modulus $E=210 \mathrm{GPa}$ and Poisson's ratio $v=0,3$. The geometrical properties of the cross section of the beams, in the succeeding examples, were calculated using the computer program given in the [14]. The two load cases are considered: the uniformly distributed axial load $p=P / h$ along the web (load case $1-\mathrm{LC} 1)$ and load case with two concentrated axial forces $P / 2$ (load case $2-$ LC2) acting at the flange tips - points A and B (Fig. 2a). In both cases, besides the axial force $N=-P$ the bimoment exist, where at the beam ends $M_{\omega 0}=-\Sigma P_{i} \omega_{(P) i}$. For the LC1 $M_{\omega 0}=-P \omega_{(\mathrm{D})}$ while for the LC2 $M_{\omega 0}=-P / 2\left(\omega_{(\mathrm{A})}+\omega_{(\mathrm{B})}\right)$ $=-P \omega_{(\mathrm{A})}-$ see Fig. $2 \mathrm{~b}$ for the warping function.

The results for LC1 and LC2 are given in Table 1 and in Fig. 3. In Table 1 the span $L$ is varied from $2,0 \mathrm{~m}$ to 6,0 $\mathrm{m}$, the web height and flange width are kept constant $h=0,30 \mathrm{~m}$ and $b=0,12 \mathrm{~m}$ while in Fig. 3 the following parameters are varied: $h=0,12 \mathrm{~m} ; 0,18 \mathrm{~m} ; 0,24 \mathrm{~m}$ the span is in the range $L=2 \mathrm{~m}$ to $6 \mathrm{~m}$, while $b=0,12 \mathrm{~m}$. In both cases the thickness is $t=0,01 \mathrm{~m}$.

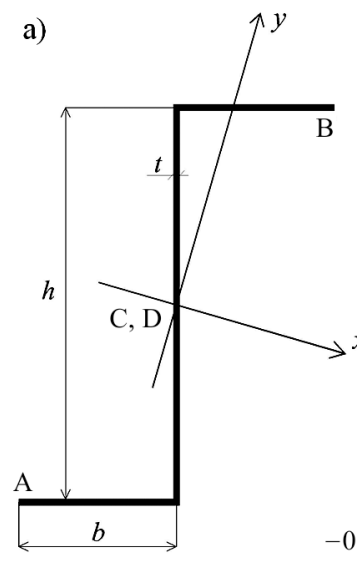

b)

Figure 2 a) The geometry of $Z$ cross section

b) Warping function $\omega\left(\mathrm{m}^{2}\right)$ for $h=0,30 \mathrm{~m}, b=0,12 \mathrm{~m}, t=0,01 \mathrm{~m}$

The buckling loads for the first torsional modes are calculated and compared with the results found by ANSYS finite element model using thin shell 4-node SHELL181 elements. The distortion of the cross section in the finite element model is suppressed by providing the transverse diaphragms infinitely rigid in the plane of the cross-section and zero out of plane stiffness. As an illustration, the first torsional buckling mode for $h=0,30$ $\mathrm{m}, b=0,12 \mathrm{~m} t=0,01 \mathrm{~m}, L=5,0 \mathrm{~m}$ obtained by ANSYS is presented in Fig. 4.

By the analysis of the results in Tab. 1 and Fig. 3 it can be seen the significant influence of the bimoment on the buckling load. If $\lambda=0$ in LC1 the underestimated values of the buckling force are obtained. On the other hand the buckling load for LC2 calculated with the presence of bimoment is considerably decreased from the critical force obtained with $\lambda=0$. The comparison with ANSYS values justifies the approach with mean value of bimoment for the global torsional stability analysis. The analysis with the exact distribution of $\lambda$ is of interest for longer spans and higher values of parameter $k$.

\begin{tabular}{|c|c|c|c|c|c|c|}
\hline \multirow[b]{2}{*}{$L(\mathrm{~m})$} & \multicolumn{3}{|c|}{ Load case 1} & \multicolumn{3}{|c|}{ Load case 2} \\
\hline & $\begin{array}{c}\text { Ansys } \\
(\mathrm{MN})\end{array}$ & $\begin{array}{c}\lambda=\lambda_{\mathrm{m}} \\
\lambda=0 \\
(\mathrm{MN})\end{array}$ & $\begin{array}{c}\text { Diff. } \\
\%\end{array}$ & $\begin{array}{c}\text { Ansys } \\
(\mathrm{MN})\end{array}$ & $\begin{array}{c}\lambda=\lambda_{\mathrm{m}} \\
\lambda=0 \\
(\mathrm{MN})\end{array}$ & $\begin{array}{c}\text { Diff. } \\
\%\end{array}$ \\
\hline 2,0 & 9,551 & $\begin{array}{c}10,033 \\
6,385 \\
\end{array}$ & $\begin{array}{c}+5,0 \\
-33,1\end{array}$ & 2,793 & $\begin{array}{l}2,809 \\
6,385 \\
\end{array}$ & $\begin{array}{c}+0,6 \\
+128,6 \\
\end{array}$ \\
\hline 3,0 & 5,287 & $\begin{array}{l}4,902 \\
3,333\end{array}$ & $\begin{array}{c}-7,3 \\
-37,0\end{array}$ & 1,498 & $\begin{array}{l}1,572 \\
3,333\end{array}$ & $\begin{array}{c}+4,9 \\
+122,6\end{array}$ \\
\hline 4,0 & 3,420 & $\begin{array}{l}3,132 \\
2,265\end{array}$ & $\begin{array}{c}-8,4 \\
-33,8 \\
\end{array}$ & 1,051 & $\begin{array}{l}1,150 \\
2,265\end{array}$ & $\begin{array}{c}+9,4 \\
+115,5 \\
\end{array}$ \\
\hline 5,0 & 2,547 & $\begin{array}{l}2,326 \\
1,771 \\
\end{array}$ & $\begin{array}{c}-8,7 \\
-30,5\end{array}$ & 0,867 & $\begin{array}{l}0,965 \\
1,771\end{array}$ & $\begin{array}{c}+11,3 \\
+104,3 \\
\end{array}$ \\
\hline 6,0 & 2,073 & $\begin{array}{l}1,894 \\
1,502\end{array}$ & $\begin{array}{c}-8,6 \\
-27,5\end{array}$ & 0,766 & $\begin{array}{l}0,871 \\
1,502\end{array}$ & $\begin{array}{l}+13,7 \\
+96,1\end{array}$ \\
\hline
\end{tabular}

Table 1 Torsional buckling forces for Z section $(h=0,30 \mathrm{~m}, b=0,12 \mathrm{~m}, t=0,01 \mathrm{~m})$ calculated by ANSYS and theoretically $\left(\lambda=\lambda_{\mathrm{m}}\right.$ bimoment considered, $\lambda=0$ bimoment not considered). Diff. $=($ Theory-Ansys $) /$ Ansys $\times 100$ 

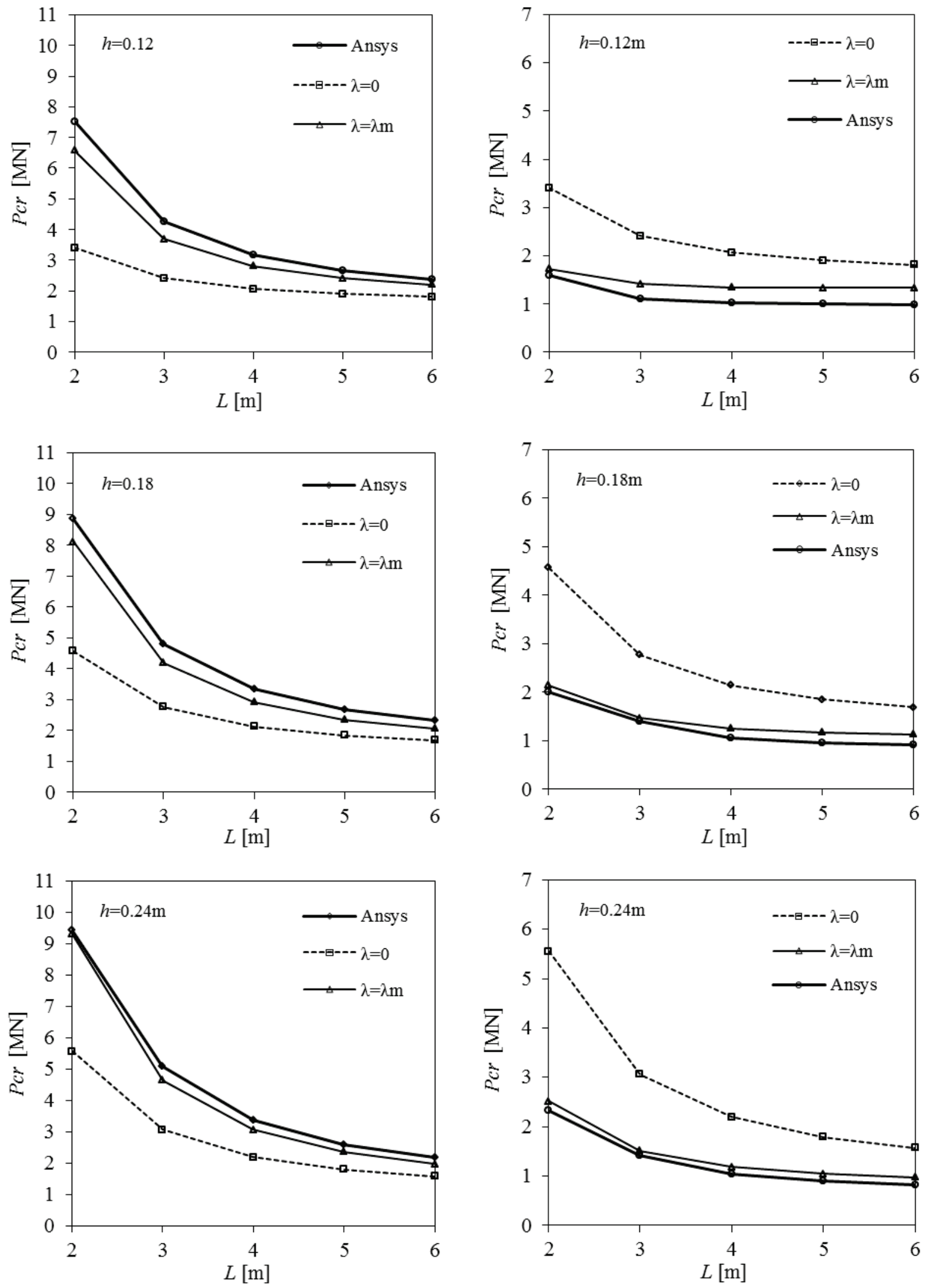

Figure 3 Torsional buckling forces (MN) for Load case 1 (left) and Load case 2 (right). $\lambda=\lambda_{\mathrm{m}}$ bimoment considered, $\lambda=0$ bimoment not considered $(b=0,12 \mathrm{~m}, t=0,01 \mathrm{~m})$ 


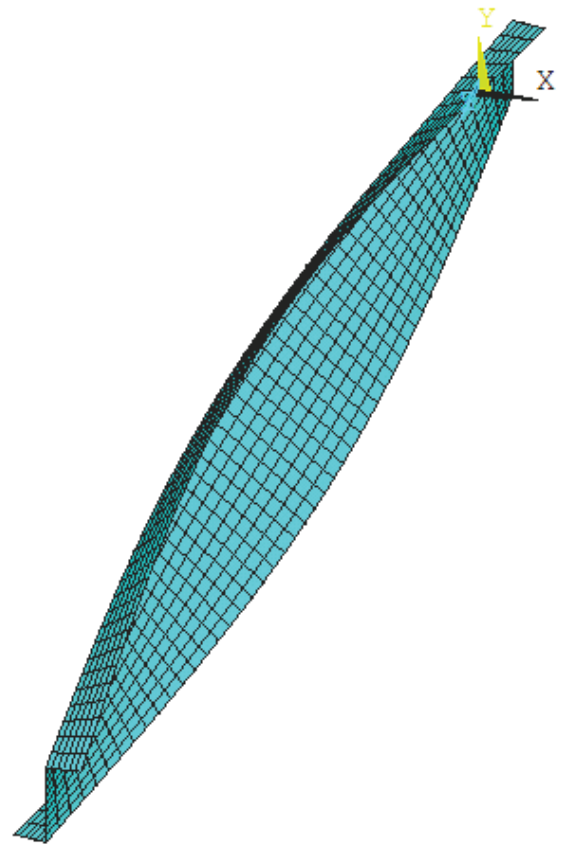

Figure 4 First torsional buckling mode Load case 1 $h=0,30 \mathrm{~m}, b=0,12 \mathrm{~m}, t=0,01 \mathrm{~m}, L=5,0 \mathrm{~m}$

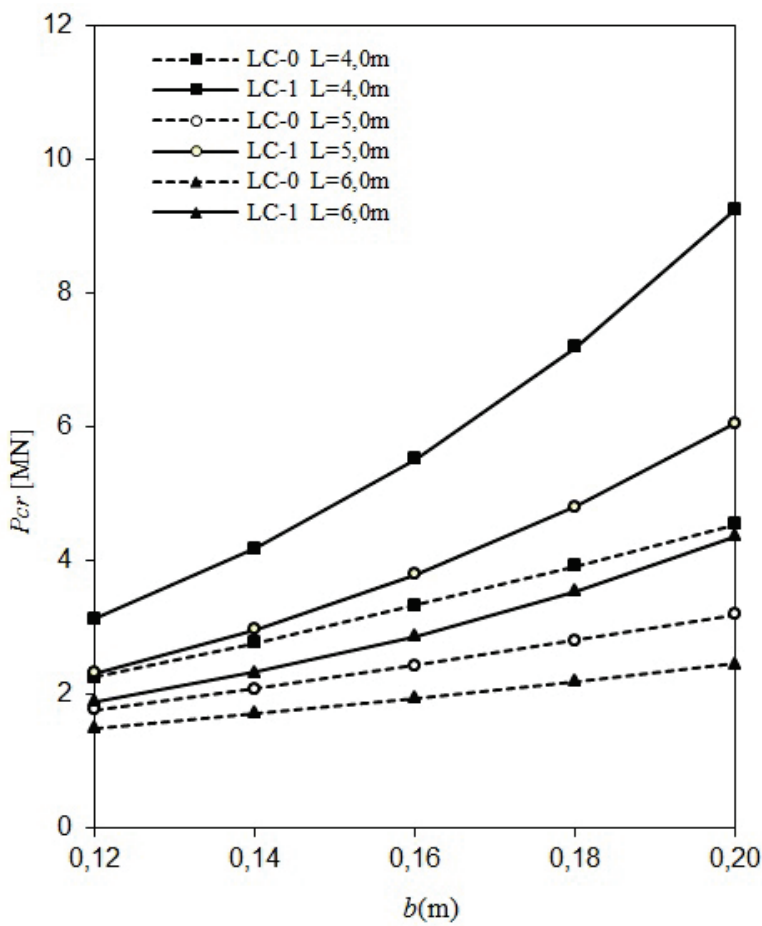

Figure 5 Influence o flange width $b$ on torsional buckling force (MN) $h=0,30 \mathrm{~m}, t=0,01 \mathrm{~m}$

In the next example the thin-walled beam with $\mathrm{Z}$ section is subjected to axial load uniformly distributed at the end cross-sections (load case LC0). In this case no bimoment is produced $(\lambda=0)$. In Fig. 5 this load case is compared with the load case LC1 in order to demonstrate the influence of flange width and span length on the buckling load. Note that influence of the flange width is more pronounced in the presence of bimoment.

\section{Conclusions}

The influence of the bimoment on the torsional bifurcation stability of thin-walled beams with open cross-section subjected to axial loads is presented. The governing equations are based on the classical (Vlasov's) theory. The torsional stability of simply supported beam with $Z$ cross-section due to different axial load distributions at beam ends is studied and the analytically calculated critical loads are compared with the results obtained by the finite element model. Obtained results clearly demonstrate the significant influence of the bimoment induced by axial loads on the global elastic torsional critical load. For other cross-sections with lack of symmetry and the compressed beams with other boundary conditions, the contribution of the bimoment to the stability analysis has to be investigated.

\section{Acknowledgements}

The present work has been supported by the Ministry of Education, science and technological development of the Republic of Serbia (Project No. ON174027).

\section{References}

[1] Eurocode 3: Design of steel structures - Part 1-1: General rules and rules for buildings, CEN, Brussels, 2005.

[2] Vlasov, V. Z. Thin-walled beams, Gosstroiizdat, Moscow [in Russian], 1940.

[3] Casafont, M.; Marimon F.; Pastor, M. M. Calculation of Pure Distortional Elastic Buckling Loads of Members Subjected to Compression via the Finite Element Method. // Thin-Walled Structures. 47, (2009), pp. 701-729

[4] Ádány, S.; Schafer, B. W. Buckling Mode Decomposition of Single-branched Open Cross-section Members via Finite Strip Method: Derivation. // Thin-Walled Structures. 44, (2006), pp. 563-581.

[5] Goncalves, R.; Dinis, P. B.; Camotim, D. GBT Formulation to Analyse the First-order and Buckling Behaviour of Thinwalled Members with Arbitrary Cross-sections. // ThinWalled Structures. 47, (2009), pp. 583-600.

[6] Timoshenko, S. P.; Gere, J. M. Theory of elastic stability. McGraw-Hill, New York, 1961.

[7] Trahair, N. S. Flexural-torsional Buckling of Structures. Glasgow, New York, Tokyo, Melbourne, Madras, F\&FN Spon, an imprint of Chapman \& Hall, London. 1993.

[8] Murray, N. W. Introduction to the Theory of Thin-walled Structures. Clarendon Press, Oxford, 1984.

[9] Chajes, A. Principles of Structural Stability Theory, Prantice-Hall, Englewood Cliffs, New Jersey, 1974.

[10] Chen, W. F.; Atsuta T. Theory of Beam-Columns, Vol. 2, Space Behavior and Design, McGraw-Hill, New York, 1977.

[11] Hajdin, N. A Contribution to the Non-linear Theory of Thin-walled Member with Open Cross-section // Bulletin: Acadèmie Serbe des Sciences et des Arts. Classe des Sciences techniques. 16, (1980), pp. 1-12.

[12] Bažant, Z. P.; Cedolin, L. Stability of Structures. Oxford Univ. Press, New York, 1991.

[13] Kim, M. Y.; Chang, S. P.; Kim, S. B. Spatial Stability Analysis of Thin-Walled Space Frames. // International Journal for Numerical Methods in Engineering. 30, (1996) pp. 499-525.

[14] Prokić, A. Computer program for determination of geometrical properties of thin-walled beams with openclosed section. // Comput. Struct. 74, (2000), pp. 705-715. 


\section{Appendix}

Geometric properties of the cross section

$A=$ cross-sectional area

$t=$ plate element thickness

$$
\begin{aligned}
& I_{x x}=\int_{A} x^{2} \mathrm{~d} A, \quad I_{y y}=\int_{A} y^{2} \mathrm{~d} A, \quad I_{\omega \omega}=\int_{A} \omega^{2} \mathrm{~d} A, \\
& K=\frac{1}{3} \int_{s} t^{3} \mathrm{~d} s \\
& i_{\mathrm{D}}^{2}=\left(\frac{I_{x x}+I_{y y}}{A}+x_{\mathrm{D}}^{2}+y_{\mathrm{D}}^{2}\right) \\
& \beta_{x}=\frac{\int_{A} x\left(x^{2}+y^{2}\right) \mathrm{d} A}{2 I_{x x}}-x_{\mathrm{D}} \\
& \beta_{y}=\frac{\int_{A} y\left(x^{2}+y^{2}\right) \mathrm{d} A}{2 I_{y y}}-y_{\mathrm{D}} \\
& \beta_{\omega}=\frac{\int_{A} \omega\left(x^{2}+y^{2}\right) \mathrm{d} A}{I_{\omega \omega}}
\end{aligned}
$$

Internal forces

$$
\begin{aligned}
& N=\int_{A} \sigma_{z z} \mathrm{~d} A, \quad Q_{y}=\int_{A} \sigma_{z y} \mathrm{~d} A, \quad Q_{x}=\int_{A} \sigma_{z x} \mathrm{~d} A, \\
& M_{y}=\int_{A} y \sigma_{z z} \mathrm{~d} A, M_{x}=\int_{A} x \sigma_{z z} \mathrm{~d} A, \quad M_{\omega}=\int_{A} \omega \sigma_{z z} \mathrm{~d} A, \\
& T_{\mathrm{D}}=\int_{A}\left(\left(x-x_{\mathrm{D}}\right) \sigma_{z y}-\left(y-y_{\mathrm{D}}\right) \sigma_{z x}\right) \mathrm{d} A \\
& T_{\mathrm{SV}}=\int_{A} 2 e \sigma_{z s} \mathrm{~d} A, T_{\omega}=T_{\mathrm{D}}-T_{\mathrm{SV}}
\end{aligned}
$$

External loads

$$
\begin{aligned}
& p_{x}=\int_{s} \bar{p}_{x} \mathrm{~d} s, \quad p_{y}=\int_{s} \bar{p}_{y} \mathrm{~d} s, \quad p_{z}=\int_{s} \bar{p}_{z} \mathrm{~d} s, \\
& m_{x}=\int_{s} \bar{p}_{z} x \mathrm{~d} s, m_{y}=\int_{s} \bar{p}_{z} y \mathrm{~d} s, \quad m_{\omega}=\int_{s} \bar{p}_{z} \omega \mathrm{d} s, \\
& m_{\mathrm{D}}=\int_{s}\left[\bar{p}_{y}\left(x-x_{\mathrm{D}}\right)-\bar{p}_{x}\left(y-y_{\mathrm{D}}\right)\right] \mathrm{d} s, \\
& \tilde{m}_{\mathrm{D}}=\int_{s}\left[\bar{p}_{x}\left(x-x_{\mathrm{D}}\right)-\bar{p}_{y}\left(y-y_{\mathrm{D}}\right)\right] \mathrm{d} s .
\end{aligned}
$$

\section{Authors' addresses}

Aleksandar Prokić, Professor, Dr. Sc.

University of Novi Sad, Faculty of Civil Engineering in Subotica Kozaračka 2a, 24000 Subotica, Serbia

E-mail: aprokic@eunet.rs

Rastislav Mandić, Assoc. professor, Dr. Sc.

University of Belgrade, Faculty of Civil Engineering Bulevar kralja Aleksandra 73, 11000 Belgrade, Serbia E-mail: rale@grf.bg.ac.rs

\section{Martina Vojnić-Purčar, PhD Student}

University of Novi Sad, Faculty of Civil Engineering in Subotica Kozaračka 2a, 24000 Subotica, Serbia

E-mail: vojnicmartina@yahoo.com

Radomir Folić, Professor Emeritus, Dr. Sc.

University of Novi Sad, Faculty of Technical Sciences

Trg Dositeja Obradovića 6, 21000 Novi Sad, Serbia

E-mail: folic@uns.ac.rs 